Berridge, N. J. \& Barrett, J. (1952). J. gen. Microbiol. 6, 14-20.

\title{
A Rapid Method for the Turbidimetric Assay of Antibiotics
}

\author{
By N. J. BERRIDGE AND J. BARRETT \\ National Institute for Research in Dairying, University of Reading
}

SUMMARY: By using a culture of Streptococcus agalactiae in its logarithmic phase of growth as test organism, it is possible to assay nisin satisfactorily with an incubation period of approximately half an hour. Penicillin, streptomycin, aureomycin and gramicidin cause a qualitatively similar response in the test organism. A similar technique could therefore be used to assay these antibiotics.

A considerable number of turbidimetric assay methods have been described (see, for example, Florey, Chain, Heatley, Jennings, Sanders, Abraham \& Florey, 1949). One of the most rapid of these was due to Lee, Foley, Epstein \& Wallace (1944), who used a streptococcus of group B and incubated until a sufficient turbidity had developed, 'usually for $90 \mathrm{~min}$. or less'. For the sake of rapidity Friedmann \& Beach (1951) used Streptococcus cremoris in nisin assays; resazurin was employed as an indicator of bacterial growth, enabling assays to be read after $20 \mathrm{~min}$. A standard error 'of the order of $10 \%$ ' was claimed for five estimations. In the work to be described Strep. agalactiae was preferred, since previous experience had shown Strep. cremoris to be sensitive to antibiotics which had little effect against pathogens.

The properties of nisin which affect its assay have been discussed by Hirsch (1950), who has also described two other methods of assay, one based on the bactericidal properties of nisin, the other on its property of prolonging the lag phase of growth of the test organism (Hirsch, 1950). The former method is also of low reproducibility, but the latter has an accuracy varying from \pm 7 to $\pm 15 \%$, and is therefore far more accurate than any of the earlier methods. However, a rapid assay was desired and a comparison of Fig. 2 in the paper by Pope (1948) with the work of Bond \& Davies (1948) suggested the method described below.

The present assay is simply carried out by making dilutions of unknown samples in powers of 2 in $0.01 \mathrm{~N}-\mathrm{HCl}$, including in each batch at least one set of tubes containing a standard solution diluted in powers of $\mathbf{1 . 5}$, 'inoculating' each tube with six volumes of a culture in the logarithmic phase of growth, and after $30 \mathrm{~min}$. incubation, halting the growth and determining the optical densities of the appropriate suspensions. Graphical comparison in the usual way between unknown and standard tubes gives the nisin content of the former.

\section{METHODS}

Definitions. (a) Units; see Mattick \& Hirsch (1947) and Berridge (1949). One unit normally delays the growth of Strep. agalactiae in $1 \mathrm{ml}$. of broth for about $16 \mathrm{hr}$. (b) Optical density (o.D.); this is the difference in Spekker 
readings on the logarithmic scale between clear broth and the culture being examined. A $4 \mathrm{~cm}$. cell was used.

The cleaning of glassware. This was done by soaking overnight in 0.01 $\mathrm{N}-\mathrm{NaOH}$ which destroys traces of nisin adsorbed by the glass.

Maintenance of culture. Stock cultures of Strep. agalactiae were kept in bullock heart medium. Cultures for daily use were propagated in Y.G.P. (Yeastrel glucose peptone broth) twice daily. This, it is believed, helped to maintain a rapidly growing strain. During week-ends the culture was refrigerated. Cultures freshly taken from stock were sometimes unsatisfactory as to growth rate, but daily passage for about a week through bullock heart medium restored each culture to normal.

The medium for assays. Yeastrel glucose broth, glucose Lemco broth and the medium of Bond \& Davies (1948) were all found satisfactory. Medium to be used on the day of working was merely steamed and filtered, the usual autoclaving being omitted. The complete coagulation of protein and efficient filtration are, however, important.

The preparation and maintenance of a culture in the logarithmic phase of growth. Each evening $10 \mathrm{ml}$. of Y.G.P. was inoculated with a loopful of 7-8 hr. culture, and placed in cold tap-water $\left(10-15^{\circ}\right)$ in an apparatus which raised the temperature to $40^{\circ}$ after about $10 \mathrm{hr}$. A time switch and thermostat were used on some occasions; on others $300 \mathrm{ml}$. of the cold water were placed in a litre vacuum flask in an incubator. In the morning the culture $(10 \mathrm{ml}$.) was added to $100 \mathrm{ml}$. of warm Y.G.P.; this was further diluted while the streptococci were still actively growing, and within $2 \mathrm{hr}$. a litre or two of broth was ready for assays. Aseptic precautions were not observed beyond this stage. The culture was kept in its logarithmic phase merely by diluting before the optical density reached its maximum. This was at first controlled by Spekker readings, but since there is a wide margin of safety a little practice permitted it to be done by eye. Thus, when the culture looked dense enough (0.D. 0.5) it was diluted 10- to 20-fold and could be left for an hour.

The culture for assays. The logarithmic phase culture was diluted by stages, keeping the o.D. between 0.02 and 0.05 until the volume required was obtained, and was finally adjusted to an o.D. of between $0 \cdot 17$ and 0.25 just before use.

Diluting the antibiotic. This process was carried out in a modified $5 \mathrm{ml}$. syringe. A stop, e.g. a 'Meccano' collar or a pile of washers, was fitted on the stem just above the plunger so that the capacity of the syringe was limited to $5 \cdot 0 \mathrm{ml}$. A spring was fitted between the barrel cover and the handle of the stem so that its force raised the plunger with a brisk motion to its highest point. This spring was cut to such a length that when it was completely compressed the plunger reached only the $2.5 \mathrm{ml}$. mark. A suitable spring was made from a standard 'Meccano' spring by pulling it out and cutting off the required length. The syringe was first filled with $0.01 \mathrm{~N}-\mathrm{HCl}$, the plunger brought to the $2.5 \mathrm{ml}$. mark and $2.5 \mathrm{ml}$. of the antibiotic solution were sucked in; $\mathbf{2 . 5} \mathrm{ml}$. of the mixture were then ejected into the first assay 
tube and the operation repeated as required. Beginning with a nisin predilution containing 4.0-200 units $/ \mathrm{ml}$, seven such doubling dilutions were made. The cycle of dilution followed by emptying, rinsing and refilling the syringe can be completed in 47 sec. An allowance of 1.5 min. per assay for this part of the work thus allows time for careful operation.

With the syringe technique there is a risk of contaminating with nisin the bulk of the broth used for dilution every time the syringe is put into it. Contrary to expectation this contamination proved negligible in practice. Experiments with coloured solutions showed that with a smooth technique of normal speed the contaminated solution near the tip of the syringe was sucked into the syringe on the upward stroke. The precautions were therefore limited to the use of a small beaker for the diluting medium, emptying and rinsing the beaker once, and the syringe twice between each set of dilutions. The traces of nisin which remained on the sides of the plunger seemed to be insufficient to affect the assay. Titrations confirmed that an acid could be diluted accurately by this technique.

Adding the test culture. Into each tube $15 \mathrm{ml}$. of the culture at $40^{\circ}$ were rapidly pumped with sufficient tangential force to wash the sides and to ensure thorough mixing without foaming. A hand-operated ampoule-filling machine (A. J. Manning Ltd., Wembley) enabled 100 tubes to be filled in less than $3 \mathrm{~min}$.

Incubation. Bond \& Davies (1948) found Staphylococcus aureus in penicillin to be sensitive to minor fluctuations of temperature. The response of $S t r e p$. agalactiae to nisin does not show such a sensitivity so that special precautions were not required; any temperature between 37 and $44^{\circ}$ may be used, but $40^{\circ}$ was preferred as it gave the maximum growth rate. Half an hour was a convenient short period for incubation. On the few occasions when $1 \mathrm{hr}$. has been used, a greater slope has been obtained, but this does not necessarily give an increase in accuracy (Wood, 1948).

Halting the growth. The addition of $5 \mathrm{ml}$. of $0.004 \%$ thiomersalate (ethyl mercurithiosalicylate) halted the growth immediately, giving a mixture which maintained a constant turbidity for about $24 \mathrm{hr}$. The thiomersalate must be injected with sufficient force to cause immediate and thorough mixing. This was done with the ampoule-filling machine, but using a finer jet than that used for filling.

Measuring the optical density. A Spekker absorptiometer was used with an Ilford light filter no. 608 and the $4 \mathrm{~cm}$. cell. Because of the long chains of streptococci, turbulence in the cell caused irregular readings. An inconveniently long time was needed for turbulence to disappear, and therefore two baffles, consisting of ill-fitting glass plates at right angles to the light beam, were cemented into the cell leaving small gaps here and there around the edges. In this way turbulence was eliminated and measurements could be made without delay.

\section{Interpretation}

The optical densities in the tubes containing the standards were plotted against the nisin concentrations, and the best straight line drawn by judge- 
ment, as exemplified in Figs. 1-4, to give a graph from which the unknown nisin concentrations could be read. The straight line usually extended over a three-fold range of nisin concentration, beginning most frequently at c. 2.5 units/tube, though occasionally starting as low as 1 or as high as 4 units/tube. For the special purposes of Figs. 2-4 dilutions in powers of $4 / 3$ were used. Normally powers of $3 / 2$ were used in the standard series.

With a series of dilutions for each unknown it was often possible to obtain two readings for each nisin solution, corresponding to two levels of the standard. With solutions similar to the standard these two readings agreed. When, as frequently happened, there was disagreement arising from the presence of different antibiotics for which no standard was available, it was a matter of definition as to which level should be taken to indicate equality. The level corresponding to the range $3 \cdot 5-7 \cdot 0$ units/tube was chosen. In order to achieve some replication in one batch of assays, it was possible to tabulate the values for the unknowns falling in the preferred range alongside the value for the tubes in the next higher or lower range (according to which extra point fell in the usable range of the standard graph), and thus to calculate for each unknown the factor relating the concentration in the high or low range to that in the preferred range. By doing this with a whole batch of, say, twenty assays of a particular preparation of nisin and taking the average for each of the two kinds of factor, it was possible to reach a presumably reliable average for each factor. Then, using this average in place of the expected 2.0 or 0.5 , the values in the preferred range could be calculated from those of the lower or higher ranges. Thus duplicate and sometimes triplicate values could be obtained from one assay. Ratios varying from 1.78 in one case to 2.18 in another were obtained.

\section{RESULTS}

\section{With nisin}

A series of twenty-five consecutive duplicated assays done on several different days (during work on counter current distribution) was subjected to the analysis of variance as described by Patterson (1939). In order to avoid mixing very large with very small values, the figures as derived for the total number of units present in the chosen assay tubes were used. It seems to be the general experience that agreement of such assays on any one day is relatively close, but that variations from day to day can be great. Therefore instead of replicating tubes during each assay, the whole assay was repeated on a different day. The standard deviation therefore includes day-to-day variations. The values ranged from 2.9 to $7 \cdot 2$ units/tube, the mean being 4.64. The standard deviation was 0.42 unit or $9 \cdot 0 \%$ of the mean.

In a similar range of assays of crudest nisin, in which the duplicates were done on the same day, the standard deviation was $5.9 \%$ of the mean.

In a third set of thirteen samples, nine were duplicated immediately after the first set had been diluted, and all twenty-two assays were made with the same culture. The nine duplicates gave consistently lower figures than the corresponding values in the first set, the average difference being 0.3 unit/tube, 
i.e. about $6 \%$. By allowing for the difference in 'slope' (as described under 'Interpretation') so that two readings were obtained for each assay, and by adding the constant difference of $\mathbf{0 . 3}$ unit to each duplicate, it was possible to decrease the standard deviation in this series to $3 \cdot 6 \%$ of the mean. Under these conditions, therefore, duplicate assays are sufficient to discover differences greater than $10 \%(t=2 \cdot 26$ at $P=0.05$ for 9 degrees of freedom).

Table 1. Standard deviations of rapid assay under various conditions

\begin{tabular}{|c|c|c|c|c|c|}
\hline Antibiotic & $\begin{array}{l}\text { No. of } \\
\text { different } \\
\text { samples }\end{array}$ & $\begin{array}{l}\text { No. of } \\
\text { replicates } \\
\text { from each } \\
\text { sample }\end{array}$ & $\begin{array}{c}\text { Range } \\
\text { of } \\
\text { variates }\end{array}$ & $\begin{array}{c}\text { Standard } \\
\text { deviation } \\
\text { as \% of } \\
\text { general mean }\end{array}$ & Notes \\
\hline Nisin & 25 & 2 & $2 \cdot 9-7 \cdot 2$ & $9 \cdot 0$ & $\begin{array}{l}\text { Duplicates assayed } \\
\text { on different days }\end{array}$ \\
\hline Nisin & 12 & 2 & $1 \cdot 8-7 \cdot 7$ & $5 \cdot 9$ & - \\
\hline Nisin & 9 & 2 & $4 \cdot 1-7 \cdot 8$ & $3 \cdot 6$ & $\begin{array}{l}\text { Allowance made for } \\
\text { differences in 'slope" } \\
\text { and for time between } \\
\text { duplicates }\end{array}$ \\
\hline Nisin & $\mathbf{1}$ & 10 & - & $4 \cdot 3$ & Incubation: $40 \mathrm{~min}$. \\
\hline Penicillin & 1 & 9 & - & $4 \cdot 7$ & Incubation: $30 \mathrm{~min}$. \\
\hline Penicillin & 1 & 10 & - & $\mathbf{2 \cdot 2}$ & Incubation: $60 \mathrm{~min}$. \\
\hline
\end{tabular}

It has occasionally been said that solutions of nisin deteriorate. In our experience such deterioration has been the result of mould growth of a character easily to be mistaken for a slight precipitate. The following figures, which are not exceptional, indicate the stability of standard solutions. An approximately $1 \%$ solution of standard powder in $0.05 \mathrm{~N}-\mathrm{HCl}$ had, when fresh, an activity of 16,500 units/ml. by definition. It was kept in the refrigerator $\left(0-2^{\circ}\right)$ for 8 months, and when compared with a fresh solution of standard its activity was found to be 16,200 units $/ \mathrm{ml}$.

\section{Application to other antibiotics}

Figs. 1-4 show the relation between dilution and optical density when different antibiotics were tested by the technique here described. For each antibiotic a different scale was used such that the graphs approached or coincided at about $30 \%$ inhibition. The different ages of the antibiotic samples made comparison on a weight basis useless. The similarity of form between the curves indicated that the method would probably be applicable to all these substances. In spite of the lower slope of the graph for penicillin it could be assayed using $30 \mathrm{~min}$. incubation with about the same reproducibility as nisin. When, however, penicillin assays were incubated for $1 \mathrm{hr}$. starting at half the usual optical density, the graph became much steeper and the standard deviation was considerably decreased.

The results are collected in Table 1.

\section{DISCUSSION}

The effect of time noted in the last experiment with nisin described under 'Results' is small and irregular. It frequently appeared less strongly between duplicate runs with standards, and needs further investigation. This is one 
example of several ill-defined effects which combine to make the assay of nisin difficult. They are usually ascribed to its surface activity, since it is

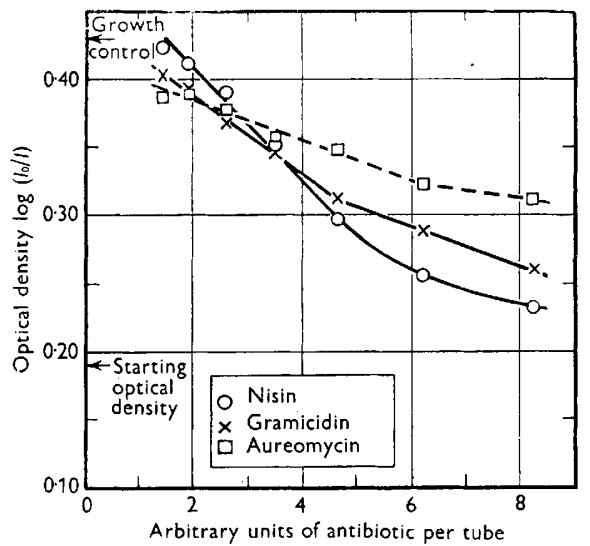

Fig. 1

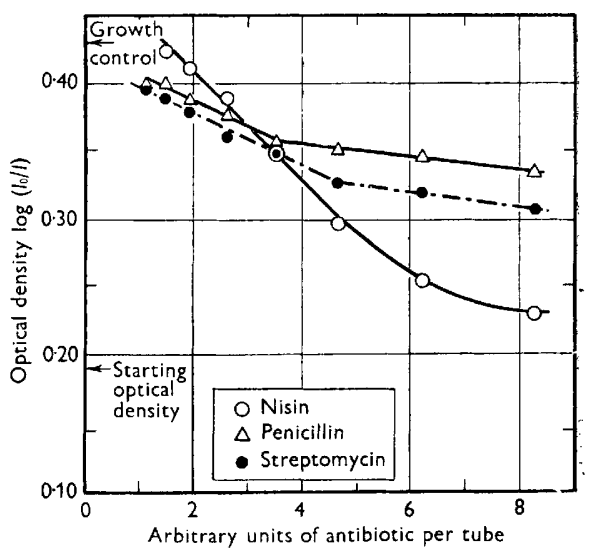

Fig. 2

Figs. 1 and 2. Response of Strep. agalactiae to different antibiotics; incubation period 30 min.

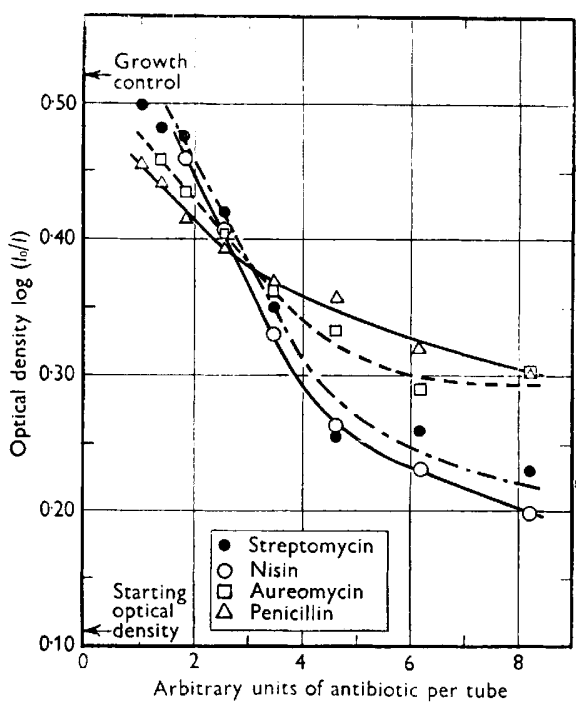

Fig. 3

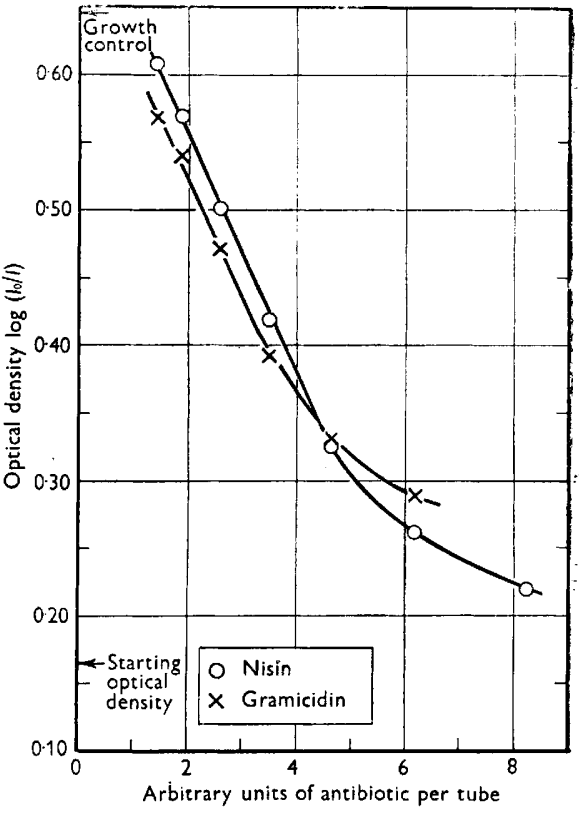

Fig. 4

Figs. 3 and 4. Response of Strep. agalactiae to different antibiotics; incubation period $60 \mathrm{~min}$.

readily adsorbed and tenaciously held by a wide variety of substances (Berridge, 1949). This probably explains an experience with inadequately steamed broth which contained a slight haze and gave erratic results. 
This technique, with minor modifications, has been used with satisfaction for about 2 years. A short incubation period was preferred in the first place because results were desired with the minimum of delay. There is, however, an a priori reason for expecting short incubation periods to give more accurate results, for the moment a culture of micro-organisms is divided, fortuitous causes begin to operate and to cause divergencies. The shorter the time between the division of the culture into separate assay tubes and the final readings, the less these divergencies should be. The less also will be the turbidity differences upon which the assay depends. There will thus be an optimum incubation time which may depend on the test organism, the antibiotic and the conditions of assay. It was not the purpose of this work to discover the optimum, but to show that approximately half an hour is, in general, sufficient and allows satisfactory assays to be made quickly.

Our best thanks are due to Miss S. Lamb for technical assistance.

\section{REFERENCES}

Berridge, N. J. (1949). Preparation of the antibiotic nisin. Biochem. J. 45, 486.

BoND, C. R. \& DAvIES, O. L. (1948). The microbiological assay of penicillin by the turbidimetric method using Staphylococcus aureus. Analyst, 73, 251.

Florey, H. W., Chain, E., Heatiey, N. G., Jennings, M. A., Sanders, A. G., Abraham, E. P. \& Florey, M. E. (1949). Antibiotics, p. 147. London: Oxford University Press.

Friedmann, R. \& Beach, S. A. (1951). New methods of assay for the antibiotic nisin. J. gen. Microbiol. 5, v.

Hrrsch, A. (1950). The assay of the antibiotic nisin. J. gen Microbiol. 4, 70.

LeE, S. W., Foley, E. J., Epstein, J. A. \& Wallace, J. H. (1944). Improvements in the turbidimetric assay for penicillin. J. biol. Chem. 152, 485.

Matrick, A. T. R. \& Hirsch, A. (1947). Further observations on an inhibitory substance (nisin) from lactic streptococci. Lancet, ii, 5 .

Patterson, D. D. (1939). Statistical Technique in Agricultural Research, Chap. 2. London: McGraw-Hill Book Co. Inc.

Pope, C. G. (1948). The assay of penicillin by the dilution method and the differential assay of penicillin by charcoal adsorption. Analyst, 73, 247.

Woon, E. C. (1948). Discussion on methods of penicillin assay. Analyst, 73, 256.

(Received 2 March 1951) 